\title{
Chapter 7 \\ Inter-Cohort Variation in the Consequences of U.S. Military Service for Men's Mid- to Late-Life Body Mass Index Trajectories
}

\author{
Janet M. Wilmoth, Andrew S. London, and Christine L. Himes
}

Obesity, as measured by body mass index (BMI), is considered one of the most pressing public health concerns in the United States (U.S. Department of Health and Human Services 2001). Although obesity rates have recently stabilized, the prevalence of obesity in the adult population increased for all sex and age groups between 1980 and 2010 (Flegal et al. 1998, 2010; Ogden et al. 2012). In the most recent data, $35.7 \%$ of adults in the United States-over 78 million people-were considered obese (Ogden et al. 2012). Since obesity is associated with a variety of health problems, most notably diabetes (Narayan et al. 2007), and with increased disability at older ages (Himes 2000), understanding the mechanisms by which subgroups of the population do and do not gain weight as they age is important.

The obesity epidemic in the United States coincided with a substantial shift in men's participation in the U.S. military. In the middle of the twentieth century, military service early in adulthood was a normative part of the life course for the majority of men in the United States (Hogan 1981). However, in 1973, the U.S. military ended conscription and moved into the current All-Volunteer Force era. Relative to the participation rates of men from early-twentieth-century birth cohorts, which peaked around $80 \%$ for those who served during World War II (Hogan 1981), rates of military service among young adults in more recent cohorts have dropped substantially. Nevertheless, military service remains a salient pathway to adulthood for many young adults in the United States (Wilmoth and London 2013; Wolf et al. 2013). If military service influences weight and weight gain across the life course, then the passage of cohorts through the age structure during historical

J.M. Wilmoth $(\bowtie) \cdot$ A.S. London

Department of Sociology and Aging Studies Institute, Syracuse University, Syracuse, NY, USA

e-mail: jwilmoth@maxwell.syr.edu

C.L. Himes

Lewis College of Human Sciences, Illinois Institute of Technology, Chicago, IL, USA

(C) The Author(s) 2015

C. Burton-Jeangros et al. (eds.), A Life Course Perspective on Health Trajectories

and Transitions, Life Course Research and Social Policies 4,

DOI 10.1007/978-3-319-20484-0_7 
periods characterized by different levels of early-adulthood engagement in military service could contribute to population-level changes in age-specific obesity rates.

At the individual-level, military service is a potential source of variation in BMI outcomes that is often overlooked in the extant literature. A growing body of life course research examines the health consequences of service in the U.S. military in different historical periods (Dobkin and Shabani 2009; Elder et al. 1997; MacLean 2013; Teachman 2011; Whyman et al. 2011; Wilmoth et al. 2010). However, until recently (Teachman and Tedrow 2013), researchers have not focused much attention on veteran status differences in BMI or whether military service affects changes in BMI over the life course. One consequence of this omission is that there is little evidence regarding the importance of veteran status relative to other individual-level characteristics that are commonly examined in the BMI literature, such as childhood disadvantage, race/ethnicity, socioeconomic status, and health behaviors. Given that the military carefully screens the health and body weight of those who enlist or are inducted into service (Poston et al. 2005; Wolf et al. 2013), and early-life weight is a strong predictor of later-life weight (Ferraro et al. 2003), veterans might be expected to weigh less and have a lower prevalence of obesity than non-veterans. However, somewhat paradoxically, previous research shows that body weight among veterans is generally similar to or higher than body weight among non-veterans (Almond et al. 2008; Wang et al. 2005; Teachman and Tedrow 2013).

A well-controlled, comparative examination of BMI trajectories by veteran status has the potential to inform our understanding of the veteran status-weight paradox and shed light on the early- and later-life factors that influence change in weight over the life course more broadly. Therefore, in this chapter, we examine the relationship between service in the U.S. military and men's BMI trajectories in mid- to late-life. We are particularly interested in comparing older veterans and non-veterans within successive cohorts who were subjected to specific historical circumstances in terms of periods of war and peace, as well as dietary practices and norms regarding daily physical activity. Our approach allows us to isolate the effect of U.S. military service for given cohorts from the broader health-related trends that have driven increases in BMI in the U.S. population over time. It also provides insight into how following particular pathways in the transition to adulthood can have enduring implications for development and the influence of historical time on life course outcomes, both of which are central features of the life course perspective (Wilmoth and London 2013).

\section{Military Service and Physical Health}

There are various mechanisms by which military service in early adulthood could have effects on later-life physical health outcomes, for better or worse (Wilmoth and London 2013). In theory, military service may be associated with better health because of selection, directly beneficial effects of military service, or the indirect effects of military service on mid- to later-life health-related outcomes. Because 
of pre-induction or -enlistment screening that blocks the entry of persons with observable health problems from joining the military (Sackett and Mayer 2006), veterans may, on average, be in better health than non-veterans in earlier periods of the adult life course. Additionally, during war, active-duty personnel are screened for combat readiness, which could contribute to a "healthy warrior" effect among war-service veterans. Beyond selection, the intense physical training and fitness required of military personnel may produce health benefits or encourage life-long participation in exercise, while the resources to which veterans have access through the U.S. Department of Veterans Affairs can indirectly affect health by shaping a range of health-related outcomes, such as educational attainment (Bennett and McDonald 2013), employment and earnings (Kleykamp 2013), and marriage and family integration (Burland and Lundquist 2013). In addition, military service can operate as a positive turning point in the life course, particularly for individuals from disadvantaged socioeconomic backgrounds, because it "knifes off" prior negative influences and creates a "bridging environment" that provides access to educational, training, and health care resources (Elder 1986, 1987; London and Wilmoth 2006; Sampson and Laub 1996).

Although there are good theoretical reasons to consider, and some empirical evidence supporting, the potential benefits of military service for physical health, the bulk of the available evidence documents negative health and disability consequences. Service-related factors that could negatively impact health outcomes include: training accidents and over-training injuries; hazardous work assignments; deployment to locales with infectious disease conditions that are detrimental to health; financial strains and other stressors related to separation from family and work; the distribution of subsidized tobacco products by the military; and placement in environments that are conducive to substance use or heavy drinking (Bedard and Deschênes 2006; Clipp and Elder 1996; Elder and Clipp 1988, 1989; Elder et al. 2009). In addition, wartime service often involves combat exposure, which increases the risk of short-term injury and long-term disability (Elder et al. 1997; MacLean 2010, 2013), physical and mental health problems (Elder et al. 2009; Vogt et al. 2004), and later-life mortality (Elder et al. 2009). Thus, wartime service should have a more negative impact on later-life health than non-war service.

There is a substantial literature on the physical health of veterans that documents a high prevalence of poor health, functional limitation, and disability (Aldwin et al. 1994; Beebe 1975; Centers for Disease Control 1998; Keehn 1980; Schnurr et al. 2000). Service members and veterans who were deployed to war zones are more likely to report ill health and chronic fatigue, gastrointestinal diseases, skin disorders, and chronic pain (Armed Forces Health Surveillance Center 2009; Institute of Medicine 2008). While providing important data on the health of veterans that is useful for some policy and planning purposes, this literature usually does not directly examine differences between veterans and non-veterans, compare veterans with and without wartime service, or attempt to determine the extent to which service during particular historical periods or wars has different effects on later-life health. 
In addition to the research that focuses on veterans only, there is comparative evidence based on data from the general population that documents the enduring effects of military service on health and disability. Veterans who served during wartime, particularly World War II (WWII) and the Korean War, experience steeper later-life health declines than non-veterans (Wilmoth et al. 2010). Veteransespecially combat veterans (MacLean 2010) — also have higher rates of functional limitations and disabilities than non-veterans (Wilmoth et al. 2010). Compared to non-veterans, Vietnam War veterans are more likely to rate their health as fair or poor, have physical limitations, and be anxious or depressed (Dobkin and Shabani 2009). Similar evidence is derived from studies of more recent veterans. Recent research indicates that at age 40, veterans who served on active duty during the era of the All-Volunteer Force (which began when conscription ended in 1973) report poorer self-rated health, even after controlling for a range of covariates, including socioeconomic status and health behaviors (Teachman 2011). The higher rates of poor health, functional limitation, and disability among veterans during midlife may contribute to health disparities in later life by influencing the economic well-being of veteran families; recent research indicates that households containing disabled veterans experience an increased risk of poverty and material hardship (Heflin et al. 2012; London et al. 2011; Wilmoth et al. 2015).

\section{Military Service and Body Weight}

The effects of military service on health status may be related to the underlying effect of military service on specific health behaviors, such as drug and alcohol use, smoking, sleep, diet, and exercise (London et al. 2014; Miech et al. 2013). One specific health risk factor of current interest is obesity, which is indicated by a BMI score of 30.0 or higher (Hsu et al. 2007; Lindquist and Bray 2000). Among activeduty service members, obesity is relatively rare, although it has been increasing. In 2005, approximately $12 \%$ of active-duty military personnel had a BMI score of 30.0 or higher, compared to $5 \%$ of active-duty personnel 10 years earlier (Armed Forces Health Surveillance Center 2009) and about $35 \%$ of all adults in the United States (Ogden et al. 2012). Despite this apparent active-duty advantage, numerous studies have either found that veteran status is unrelated to body size (Almond et al. 2008; Wang et al. 2005) or that veterans are more likely to be obese than non-veterans (Koepsell et al. 2009; Teachman and Tedrow 2013). However, the research that focuses on military service and weight is mostly descriptive, often focuses on veterans only, and generally does not adequately control for early-life factors that select people into military service (Almond et al. 2008; Das et al. 2005; Nelson 2006; Rosenberger et al. 2011; for an exception, see Teachman and Tedrow 2013). Moreover, some studies focus only on users of Veterans Health Administration services (Das et al. 2005; Wang et al. 2005), which is a highly selected and disadvantaged segment of the veteran population. 
One recent life course study has contributed substantially to our understanding of the connections between military service and weight gain over the life course. In the era of the All-Volunteer Force, Teachman and Tedrow (2013) argue that eating and exercise patterns are more in balance during the active-duty period than they are during the more-sedentary veteran period. Eating habits established while in the military, when physical activity and caloric demands are relatively high, carry over into civilian life, but activity levels and exercise habits do not carry over to the same extent. As a result, during the transition to civilian life, veterans gain weight and then carry that weight with them as they age. From this perspective, the military is a protective environment to the extent that it encourages physical activity during and after the period of active duty, but is a risk environment to the extent that it encourages eating habits that can lead to weight gain.

The BMI measure is a ratio of weight to height and does not measure body fat directly. Consequently, one possible explanation for why veteran men weigh more than non-veteran men is that they have more muscle mass, resulting in a high BMI score but a low fat-to-lean body mass ratio (Koepsell et al. 2012). Physical training in the military may increase muscle mass, which increases BMI, and high BMI at one point in time generally portends high BMI at a later point in time. Rosenberger et al. (2011) studied veterans of Iraq and Afghanistan and reported that higher initial BMI was associated with greater increases in BMI over 6 years for each of the five BMI trajectory groups they identified. Koepsell et al. (2012) reported that among NHANES subjects veterans had higher weight than non-veterans by self-report and direct measurement of BMI, waist-stature ratio, and waist circumference, but were less likely than non-veterans to have $35+\%$ body fat. One implication of viewing the military as a potentially protective environment that encourages physical activity is that the establishment of early-life patterns of exercise and muscle development may be particularly beneficial to individuals who are genetically predisposed toward obesity.

With the exception of Teachman and Tedrow (2013), past studies of veteran status and body size have looked only at a point in time rather than examining the trajectory of body weight change with age. Body weight for an individual is not stable over time. Cross-sectional studies show that body weight increases through adulthood until about age 65, and then declines (Flegal et al. 1998). Longitudinal studies show mixed results with respect to the factors influencing weight gain. The long-term trajectory of BMI over adulthood shows a largely linear increase with age for both men and women (Botoseneanu and Liang 2011), although weight gain appears to slow with age (He and Baker 2004). The well-documented secular increase in obesity prevalence is reflected in longitudinal studies; the BMI trajectories of younger cohorts are steeper than those of the older cohorts examined (Clarke et al. 2009).

In the United States context, findings are mixed with respect to identifying the influence of various factors on the rate of BMI change with age. Most studies indicate that women have higher rates of weight gain with age than men (Clarke et al. 2009; He and Baker 2004; Mujahid et al. 2005; Walsemann and Ailshire 2011), although some find no gender difference (Botoseneanu and Liang 2011). Race is related to BMI trajectories, but its effects vary by gender. Black and Hispanic men 
have higher rates of weight gain (Clarke et al. 2009); however, Botoseneanu and Liang (2011) find that non-Hispanic Black men gain less weight over time than White men even though they enter middle age with higher BMI. Examinations of body weight trajectories in the Alameda County Study indicate that earlylife factors, particularly educational attainment, are important in determining the trajectory of weight change over age, especially for women (Baltrus et al. 2005). However, other studies have found no effect of education or income on weight gain (He and Baker 2004).

\section{The Current Investigation}

BMI is an important health indicator that changes with age and may be shaped in important ways by prior military service. While a high proportion of older men in the United States served in the military, to date, there has been no longitudinal, population-representative study of veteran status differences in men's mid- to latelife BMI trajectories reported in the literature. As such, the potential influence of prior military service on weight change among older men remains largely hidden. In our research, we examine veteran status differences in mid- to late-life BMI trajectories for cohorts of men born in the United States during the first half of the twentieth century. Our primary research questions are: (1) How is veteran status related to BMI in mid- to late-life?; (2) Do veterans have different BMI trajectories than non-veterans, controlling for early- and mid- to late-life characteristics?; and (3) Do the BMI trajectories of veterans and non-veterans vary depending on birth cohort?

\section{Methods}

\section{Data}

This study uses data from the 1992 to 2010 longitudinal Assets and Health Dynamics among the Oldest Old (AHEAD), Health and Retirement Study (HRS), and RAND HRS files (henceforth HRS). The analytic sample for this study includes 12,277 men born between 1895 and 1956. During the 18 years of the study, these men contributed 68,483 observations to the person-period file that we use to estimate the conditional growth curve models described below. We limit the analysis to men because less than $1 \%$ (135) of the 14,491 women in the HRS served in the military.

\section{Measures}

Dependent Variable The dependent variable for this analysis is $B M I$, which is equal to weight in kilograms/height in meters squared. Both height and weight are selfreported. 
Table 7.1 Birth cohorts by years turned 18 and age ranges in 1992 and 2010

\begin{tabular}{l|l|l|l}
\hline Cohort birth years & Years turned 18 (historical period) & Age range in 1992 & Age range in 2010 \\
\hline$<1929$ & $<1947$ (WWII) & 64 and older & 82 and older \\
\hline $1929-1936$ & $1947-1954$ (Post-WWII/Korean War) & $56-63$ & $74-81$ \\
\hline $1937-1945$ & $1955-1963$ (Cold War) & $47-55$ & $65-73$ \\
\hline $1946-1956$ & $1964-1974$ (Vietnam War) & $36-46$ & $54-64$ \\
\hline
\end{tabular}

Notes: The 1992 HRS included subjects ages 51-61 who were born between 1931 and 1941. Older subjects in our analysis were initially recruited into AHEAD, which collected data from subjects ages 70 and older in 1993. The HRS and AHEAD were merged in 1998 at the same time additional birth cohorts were recruited into the study. HRS age-eligible subjects are over the age of 50 at the time of entry into the study. For details regarding the HRS study design see http://hrsonline.isr. umich.edu/sitedocs/DesignHistory.pdf.

Independent Variables There are two focal independent variables in this analysis: veteran status and birth cohort. The HRS contains a retrospective self-report of "active military service," not including service in the military reserves. We used these data to construct a binary veteran status measure $($ yes $=1)$.

In order to facilitate comparisons between veterans and non-veterans who came of age during different time periods, we constructed a measure of birth cohort that takes into account when respondents turned age 18, which is approximately when they became eligible to serve in the military, regardless of whether they actually entered the military. We used a conservative approach in that we assumed that men who turned 18 in the year a conflict officially ended were primarily eligible for service in the subsequent time period (e.g., veteran men who turned 18 in 1955 would have primarily served after the end of the Korean War). Some veteran men who turned 18 in the year a conflict ended might have served during that conflict right before it ended or as the conflict was winding down; however, the majority of their multi-year service would have been in the subsequent time period.

We created four cohorts as shown in Table 7.1: the first was born prior to 1929 and turned 18 before the end of WWII in 1946; the second was born from 1929 to 1936 and turned 18 from 1947 to 1954, during the years after WWII and during the Korean War; the third was born from 1937 to 1945 and turned age 18 between 1955 and 1963, during the Cold War; and the fourth was born from 1946 to 1956 and turned age 18 between 1964 and 1974, during the Vietnam War. It is important to keep in mind these cohorts represent the time period in which respondents turned age 18 and therefore became eligible for service, not the specific period of service among veterans. Although the men in these cohorts were eligible to serve in the military when they turned 18, some of the veterans in the sample could have served during subsequent or multiple time periods. Those who served exclusively during the Cold War would not have been subjected to combat. Additionally, given that more military personnel serve in support roles than combat roles, it is likely that the majority of those who served during WWII, the Korean War, and the Vietnam War also did not experience direct combat; however, we are unable to determine service in war zones or combat exposure due to data limitations. 
It should be noted that the youngest subjects entered the HRS later in the study period and therefore contributed fewer person-period observations to the analysis. This is due to the design of the HRS, which initially included subjects who were ages 51-61 in 1992, who were born between 1931 and 1941, and its companion study, the AHEAD, which collected data from subjects ages 70 and older in 1993, who were born before 1924. Individuals born from 1924 to 1930 and after 1941 were not included in the HRS until it was merged with the AHEAD and moved to a steady-state design in 1998. At that point, two cohorts-one born 1924-1930 and the other born from 1942 to 1947-were added. Since 1998, additional new cohorts have been added every 6 years (Health and Retirement Study 2008).

Control and Potentially Mediating Variables The analysis includes a broad range of control and potentially mediating variables, which prior research indicates are associated with both veteran status and BMI. The first set of control variables are retrospectively reported early-life characteristics that occurred prior to military service: race/ethnicity, early-life socioeconomic disadvantage, and early-life health. Race/ethnicity includes non-Hispanic White (reference), non-Hispanic Black, nonHispanic other race, and Hispanic (of any race). Early-life socioeconomic disadvantage is an indexed scale, which is comprised of four dichotomously coded retrospective childhood variables: mother's education and father's education $(<8$ years $=1 ; \geq 8$ years $=0)$; father's occupation when the respondent was age 16 (unskilled manual $=1$, non-manual, skilled, and professional $=0$ ); and overall family SES from birth to age 16 (poor $=1$, not poor, including the family was "pretty well off financially," "about average," and "it varied" =0). Per the procedure outlined in Wilmoth et al. (2010), respondents missing on any of these four variables were assigned to the zero category for that variable, which is a conservative approach to dealing with missing data because that category represents greater advantage and misclassification would bias toward the null. We summed these four variables and divided by the number of items answered to create an early-life disadvantage scale that ranges from 0 to 1 , with higher values indicating more disadvantage. Because a relatively large proportion of respondents had missing values on at least one early-life disadvantage item, which is due primarily to father's absence or attrition prior to the 1998 survey when these questions were asked for the first time, we also include a variable in the models that is equal to one for all individuals for whom at least one of these variables was missing and set to zero. Additionally, the analysis includes a measure of health from birth to age 16 years that measures poor health and missing relative to good health (reference).

The other variables, which reference mid- to late-life characteristics that potentially mediate the relationship between military service and BMI, are measured many years after military service has ended. All of these mid- to late-life variables, except education, are time-varying across the 18-year study period. Marital status includes four categories: married (reference), never married, divorced/separated, and widowed. Education is measured at entry into the HRS and includes high 
school or less (reference), some college or college graduate, and more than college. Household income is measured in dollars. Labor force status is recoded as a binary variable (in the labor force $=1$ ). Two health behaviors are measured dichotomously: ever smoked cigarettes (yes $=1$ ) and currently drinks alcohol (yes $=1$ ).

Finally, we include three methodological controls. These are binary variables measuring ever had a proxy interview (yes $=1)$, dropping out of the study $($ yes $=1$ ), and dying during the 18-year time span of the study (yes $=1)$.

\section{Analysis Plan}

After describing the sample, we estimate conditional growth curve models using the person-period file described above and the PROC MIXED procedure in SAS. In all of these trajectory analyses, we define time in terms of chronological age (as opposed to study duration) because we are interested in modeling age-related changes in BMI. The grand mean age for all sample members, which is equal to 67 years, is used to center age.

Models include terms for age and age squared to test for nonlinearity in the relationship between age and BMI. Additionally, we include terms that interact age and age squared with the veteran status and cohort measures to account for potential nonlinearity in the slope that estimates age-related changes in BMI in relation to our focal variables. The models control hierarchically for early-life and mid- to latelife characteristics, as well as methodological controls for proxy response, attrition, and death over the study period, although the coefficients for those controls are not shown (full models are available upon request). We focus on interpreting the coefficients for the effect of veteran status and cohort membership on BMI at the mean age of 67 years, and the effect of veteran status and cohort membership on age-related change in BMI. Positive coefficients indicate that men who are veterans or in a particular cohort have higher BMI relative to the reference group, whereas negative coefficients indicate the opposite.

To facilitate the interpretation of the fully-specified model, we present predicted age-related BMI trajectories by birth cohort and veteran status. The predicted values represent men with the following characteristics: non-Hispanic White; mean earlylife disadvantage; good early-life health; high school graduate; out of the labor force; mean household income; married; never smoked; current non-drinker; never had a proxy interview; not lost to follow up; and did not die during the study period. Predicted values are only presented for the age ranges over which the birth cohorts are observed during the study period, which are shown in Table 7.1. The figure only presents predicted values at age 50 and older because the men must have been at least 50 to be eligible for inclusion in the HRS. 


\section{Results}

\section{Sample Description}

Table 7.2 presents descriptive statistics overall and by veteran status. As seen in Table 7.2, the characteristics of veterans and non-veterans differ substantially. Overall, the mean BMI is 27.4, with veterans having slightly, but significantly, lower BMI than non-veterans (27.34 versus 27.49). The mean age of the sample is 67 , but veterans are significantly older than non-veterans. The sample is fairly evenly distributed across the first three birth cohorts, with each containing less than one-third of the sample; as expected due to the design of the HRS (see discussion in Methods), the youngest cohort has a substantially smaller percentage $(11 \%)$. Consistent with the very high rates of participation in the military in and around WWII, veterans are over-represented among the oldest two cohorts, while nonveterans have relatively higher representation in the younger two cohorts.

There are significant differences between veterans and non-veterans with respect to the early-life controls. Veterans are significantly more likely than non-veterans to be non-Hispanic White (85\% versus $69 \%$ ), which is expected on the basis of the policies that prevailed prior to the end of World War II (see Lutz 2013). Interestingly, the mean childhood disadvantage index is lower among veterans than non-veterans, but, as expected, a smaller percentage of veterans report having had poor childhood health.

There are also significant veteran status differences in the potentially mediating variables. Education levels are higher among veterans, with $35 \%$ having attended or graduated from college (compared to $22 \%$ among non-veterans). Veterans are more likely to be currently out of the labor force and have mean household incomes that are significantly lower than non-veterans. Veterans are slightly more likely to be currently married (81\%) than non-veterans $(79 \%)$. In addition, veterans are significantly more likely than non-veterans to have ever smoked (76\% versus $66 \%$ ) and to currently drink alcohol (60\% versus $55 \%)$.

Finally, veterans and non-veterans differ with respect to the methodological controls. During the study period, veterans are less likely than non-veterans to have had a proxy report (19\% versus $27 \%$ ) or be lost to follow-up (16\% versus $18 \%$ ), but are somewhat more likely to have died during the course of the study (24\% versus $23 \%$ ).

\section{BMI Trajectories in Later Life}

Table 7.3 presents four models predicting BMI. Model 1, which only includes age, age squared, and veteran status, indicates that veterans have significantly lower BMI than non-veterans at the mean-centered age of 67 . In addition, as expected, for all men, BMI decreases at an increasing rate with age. 
Table 7.2 Total sample characteristics by veteran status ${ }^{\mathrm{a}}$

\begin{tabular}{|c|c|c|c|c|c|c|c|}
\hline & \multicolumn{2}{|c|}{ Total sample } & \multicolumn{2}{|c|}{ Non-veteran } & \multicolumn{2}{|c|}{ Veteran } & \multirow[b]{2}{*}{$\mathrm{p}$} \\
\hline & $\%$ & Mean & $\%$ & Mean & $\%$ & Mean & \\
\hline \multicolumn{8}{|l|}{ Variable } \\
\hline BMI & & 27.40 & & 27.49 & & 27.34 & $* * *$ \\
\hline Age (in years) & & 67.00 & & 65.62 & & 68.15 & $* * *$ \\
\hline \multicolumn{8}{|l|}{ Veteran } \\
\hline Yes & 54.52 & & & & & & \\
\hline No & 45.48 & & & & & & \\
\hline \multicolumn{8}{|l|}{ Birth cohort } \\
\hline$<1929$ & 27.17 & & 21.27 & & 32.09 & & $* * *$ \\
\hline 1929-1936 & 29.46 & & 25.00 & & 33.17 & & \\
\hline 1937-1945 & 32.19 & & 38.35 & & 27.06 & & \\
\hline $1946-1956$ & 11.18 & & 15.38 & & 7.68 & & \\
\hline \multicolumn{8}{|l|}{ Race/ethnicity } \\
\hline White & 77.13 & & 69.54 & & 85.02 & & $* * *$ \\
\hline Black & 12.63 & & 17.23 & 16.56 & 9.35 & & \\
\hline Other & 2.14 & & 3.00 & & 1.42 & & \\
\hline Hispanic & 8.10 & & 12.77 & & 4.21 & & \\
\hline Childhood disadvantage index $(0-1)$ & 0.34 & & & 0.37 & & 0.32 & $* * *$ \\
\hline \multicolumn{8}{|l|}{ Poor childhood health } \\
\hline Yes & 4.37 & & 5.41 & & 3.50 & & $* * *$ \\
\hline No & 95.63 & & 94.59 & & 96.50 & & \\
\hline \multicolumn{8}{|l|}{ Education } \\
\hline High school or less & 58.05 & & 64.81 & & 52.41 & & $* * *$ \\
\hline Attended/graduated college & 29.26 & & 22.48 & & 34.92 & & \\
\hline More than college & 12.69 & & 12.71 & & 12.67 & & \\
\hline \multicolumn{8}{|l|}{ Labor force participation } \\
\hline Yes & 31.97 & & 36.72 & & 28.01 & & $* * *$ \\
\hline No & 68.03 & & 63.28 & & 71.99 & & \\
\hline Household income (in $\$ 1,000$ ) & 62.50 & & & 64.94 & & 60.47 & $*$ \\
\hline \multicolumn{8}{|l|}{ Marital status } \\
\hline Married/partnered & 80.46 & & 79.32 & & 81.43 & & $* * *$ \\
\hline Divorced/separated & 8.37 & & 8.94 & & 7.89 & & \\
\hline Widowed & 8.29 & & 8.06 & & 8.48 & & \\
\hline Never married & 2.88 & & 3.68 & & 2.20 & & \\
\hline \multicolumn{8}{|l|}{ Ever smoked } \\
\hline Yes & 71.43 & & 66.20 & & 75.79 & & $* * *$ \\
\hline No & 28.57 & & 33.80 & & 24.21 & & \\
\hline \multicolumn{8}{|l|}{ Currently drinks alcohol } \\
\hline Yes & 57.66 & & 54.51 & & 60.29 & & $* * *$ \\
\hline No & 42.34 & & 45.49 & & 39.71 & & \\
\hline
\end{tabular}


Table 7.2 (continued)

\begin{tabular}{l|l|l|l|l|l|l|l}
\hline & \multicolumn{2}{|l|}{ Total sample } & \multicolumn{2}{l|}{ Non-veteran } & \multicolumn{2}{l|}{ Veteran } & \\
\hline & $\%$ & Mean & $\%$ & Mean & $\%$ & Mean & $\mathrm{p}$ \\
\hline Proxy report & & & & & & & \\
\hline Yes & 23.17 & & 27.34 & & 19.69 & & *** \\
\hline No & 76.83 & & 72.66 & & 80.31 & & \\
\hline Lost to follow-up & & & & & & & \\
\hline Yes & 17.29 & & 18.47 & & 16.31 & & *** \\
\hline No & 82.71 & & 81.53 & & 83.69 & & \\
\hline Died & & & & & & & \\
\hline Yes & 23.70 & & 22.81 & & 24.44 & & *** \\
\hline No & 76.30 & & 77.19 & & 75.56 & & \\
\hline
\end{tabular}

Significance: $* p<0.05 ; * * p<0.01 ; * * * p<0.001$

${ }^{a}$ Data are un-weighted

Model 2 controls for birth cohort. Interestingly, the coefficient for veteran status is now positive and marginally significant, indicating that, at the mean-centered age of 67, veterans have higher BMI than non-veterans once cohort is taken into account. This is because older cohorts, which have lower BMI than younger cohorts, include an over-representation of veterans. Compared to the cohort that came of age during WWII, each subsequent cohort has significantly higher BMI. It is noteworthy that the coefficients for the cohorts are quite large and increase by approximately 1 point with each successive cohort. Compared to the $<1929$ cohort (that turned 18 during WWII), the 1929-1926 cohort (that turned 18 during the post-WWII/Korean War period) has a BMI that is 1.24 points higher, the 1937-1945 cohort (that turned 18 during the Cold War) has a BMI that is 2.16 points higher, and the 1946-1956 cohort (that turned age 18 during the Vietnam War) has a BMI that is 3.11 points higher. With cohort controlled, the sign on the age coefficient becomes positive, while the age-squared coefficient remains negative.

Model 3 includes terms that estimate the age-related trajectories by veteran status and cohort. The coefficient for veteran remains positive, but is now significant, and the cohort coefficients continue to be relatively large and positive. In this model, the coefficients for age and age-squared are both negative, although only the agesquared term is significant. The coefficients that indicate the age-based trajectories for veterans reveal that, compared to non-veterans, BMI increases more rapidly with age for veterans (this difference is marginally significant). In addition, compared to the $<1929$ cohort, the other three cohorts experience more rapid increases in weight gain with age.

Model 4 adds controls for early- and mid- to late-life characteristics, as well as methodological controls for proxy interviews, loss to follow-up, and death. The results remain essentially the same as reported for Model 3. BMI decreases at an increasing rate with age. Veterans continue to have higher BMI at the mean-centered age, although the coefficient is marginally significant. The three younger cohorts have significantly higher BMI at the mean-centered age, compared to the WWII 
Table 7.3 Growth curve models predicting BMI trajectories

\begin{tabular}{|c|c|c|c|c|}
\hline Fixed effects & Model $1^{\mathrm{a}}$ & Model $2^{\mathrm{b}}$ & Model $3^{c}$ & Model $4^{\mathrm{d}}$ \\
\hline \multicolumn{5}{|l|}{ Total sample } \\
\hline \multirow[t]{2}{*}{ Intercept } & 27.7747 & $26.1949 * * *$ & $26.3522 * * *$ & $27.2601 * * *$ \\
\hline & $(0.061)$ & $(0.093)$ & $(0.127)$ & $(0.170)$ \\
\hline \multirow[t]{2}{*}{ Veteran } & $-0.2042^{*}$ & $0.1527+$ & $0.1985^{*}$ & $0.1759+$ \\
\hline & $(0.079)$ & $(0.079)$ & $(0.089)$ & $(0.091)$ \\
\hline \multirow[t]{2}{*}{ Age } & $-0.0228 * * *$ & $0.0078 * *$ & -0.0029 & 0.0038 \\
\hline & $(0.002)$ & $(0.003)$ & $(0.015)$ & $(0.015)$ \\
\hline \multirow[t]{2}{*}{$\mathrm{Age}^{2}$} & $-0.0044 * * *$ & $-0.0043 * * *$ & $-0.0045^{* * * *}$ & $-0.0047 * * *$ \\
\hline & $(0.001)$ & $(0.000)$ & $(0.001)$ & $(0.001)$ \\
\hline \multirow[t]{2}{*}{ 1929-1936 birth cohort } & & $1.2636^{* * *}$ & $1.0057 * * *$ & $0.8917 * * *$ \\
\hline & & $(0.110)$ & $(0.139)$ & $(0.142)$ \\
\hline \multirow[t]{2}{*}{ 1937-1945 birth cohort } & & $2.1551 * * *$ & $1.9501 * * *$ & $1.7836 * * *$ \\
\hline & & $(0.114)$ & $(0.140)$ & $(0.148)$ \\
\hline \multirow[t]{2}{*}{ 1946-1956 birth cohort } & & $3.1134 * * *$ & $3.1229 * * *$ & $2.9791 * * *$ \\
\hline & & $(0.133)$ & $(0.240)$ & $(0.253)$ \\
\hline \multirow[t]{2}{*}{ Age*veteran } & & & $0.0083+$ & 0.0068 \\
\hline & & & $(0.004)$ & $(0.004)$ \\
\hline \multirow[t]{2}{*}{$\operatorname{Age}^{2 *}$ veteran } & & & -0.0005 & $-0.0005+$ \\
\hline & & & $(0.000)$ & $(0.000)$ \\
\hline \multirow[t]{2}{*}{ Age*1929-1936 birth cohort } & & & 0.0119 & 0.0005 \\
\hline & & & $(0.015)$ & $(0.015)$ \\
\hline \multirow[t]{2}{*}{ Age $^{2 * 1929-1936 \text { birth cohort }}$} & & & 0.0016* & $0.0015^{*}$ \\
\hline & & & $(0.001)$ & $(0.001)$ \\
\hline \multirow[t]{2}{*}{ Age*1937-1945 birth cohort } & & & $0.0420 * *$ & $0.0339 *$ \\
\hline & & & $(0.016)$ & $(0.016)$ \\
\hline \multirow[t]{2}{*}{ Age $^{2 * 1937-1945 \text { birth cohort }}$} & & & $0.0033 * * *$ & $0.0032 * * *$ \\
\hline & & & $(0.001)$ & $(0.001)$ \\
\hline \multirow[t]{2}{*}{ Age*1946-1956 birth cohort } & & & 0.0616 & 0.0473 \\
\hline & & & $(0.038)$ & $(0.038)$ \\
\hline \multirow[t]{2}{*}{ Age $^{2 * 1946-1956 ~ b i r t h ~ c o h o r t ~}$} & & & 0.0037* & $0.0033+$ \\
\hline & & & $(0.002)$ & $(0.002)$ \\
\hline$-2 \log$ likelihood & $309,112.8$ & $308,510.8$ & $308,264.9$ & $308,134.3$ \\
\hline AIC & $309,134.8$ & $308,538.8$ & $308,338.9$ & $308,216.3$ \\
\hline BIC & $309,216.8$ & $308,643.1$ & $308,614.6$ & $308,521.8$ \\
\hline Number of observations & 68,483 & 68,483 & 68,483 & 68,483 \\
\hline Number of cases & 12,722 & 12,722 & 12,722 & 12,722 \\
\hline
\end{tabular}

Notes: Significance levels: $+p<0.10$; ${ }^{*} p<0.05 ; * * p 0.01 ; * * *<0.001$

${ }^{a}$ Model only includes age and veteran status variables

${ }^{b}$ Model controls for birth cohort

${ }^{\mathrm{c}}$ Model includes age-related trajectories by veteran status and birth cohort

${ }^{\mathrm{d}}$ Model controls for race/ethnicity, early-life socioeconomic disadvantage, early-life health, education, income, labor force participation, marital status, smoking, drinking, proxy interview, lost to follow up, and death during the study period 
cohort. However, the age*veteran coefficient is no longer significant, but the agesquared*veteran coefficient is marginally significant and negative, indicating that veteran BMI decreases at an increasing rate with age. For the three younger birth cohorts, BMI increases at an increasing rate with age.

Supplemental analysis suggests that the veteran status results are sensitive to model specification. While the cohort coefficients are consistently significant and large, the significance of the veteran coefficient meets the $p<0.05$ standard in some models, but is marginally significant in other models. For example, the supplemental model that only included controls for early-life characteristics found that veteran status is marginally significant. This suggests early-life characteristics that are related to selection into military service explain some of the relationship between veteran status and mid- to late-life BMI. When we add the potentially mediating mid- to late-life variables, the veteran status coefficient becomes significant at conventional levels. This indicates some of the effect of veteran status on BMI operates through mid- to late-life characteristics that are related to BMI. In the fully-specified Model 4 shown in Table 7.3, veteran status once again becomes marginally significant when the methodological controls are included. Overall, these supplemental analyses consistently show that veterans have slightly higher BMI and less rapid weight gain trajectories with age, although in some of these models these effects are marginally significant.

Although the coefficients for the covariates are not shown (results available upon request), it is noteworthy that BMI is significantly higher among respondents who currently drink alcohol (compared to those who do not drink alcohol), and significantly lower among respondents who are other race (compared to nonHispanic Whites), have college or graduate education (compared to those with a high school education or less), are divorced/separated, widowed, or never married (compared to currently married), ever smoked (compared to never smoked), ever had a proxy interview (compared to those who never had a proxy interview), and died during the study period (compared to those who did not die). Childhood disadvantage, childhood health, Black and Hispanic race/ethnicity, and household income are not significant in the fully specified model.

Figure 7.1 presents the age-based BMI trajectories by cohort and veteran status that are based on the fully-specified Model 4 in Table 7.3. The figure demonstrates that, within each cohort, veterans are modestly heavier than non-veterans at every age. Also, the overall pattern of the BMI trajectories for veterans and non-veterans within each cohort is similar, which suggests that military service has a consistent effect on mid- to late-life BMI trajectories regardless of cohort. The observed crosscohort differences in BMI trajectories are noteworthy, as they are substantially larger than the observed intra-cohort effect of veteran status. Each successive cohort is heavier and appears to exhibit more rapid weight gain early in later-life. The difference in BMI across cohorts at age 65, which is an age at which all of the cohorts were actually observed in the data, is substantial. For example, the predicted BMI at age 65 for the $<1929$ cohort is just under 27.5 , whereas it is nearly 30.5 for the 1946-1956 cohort. 


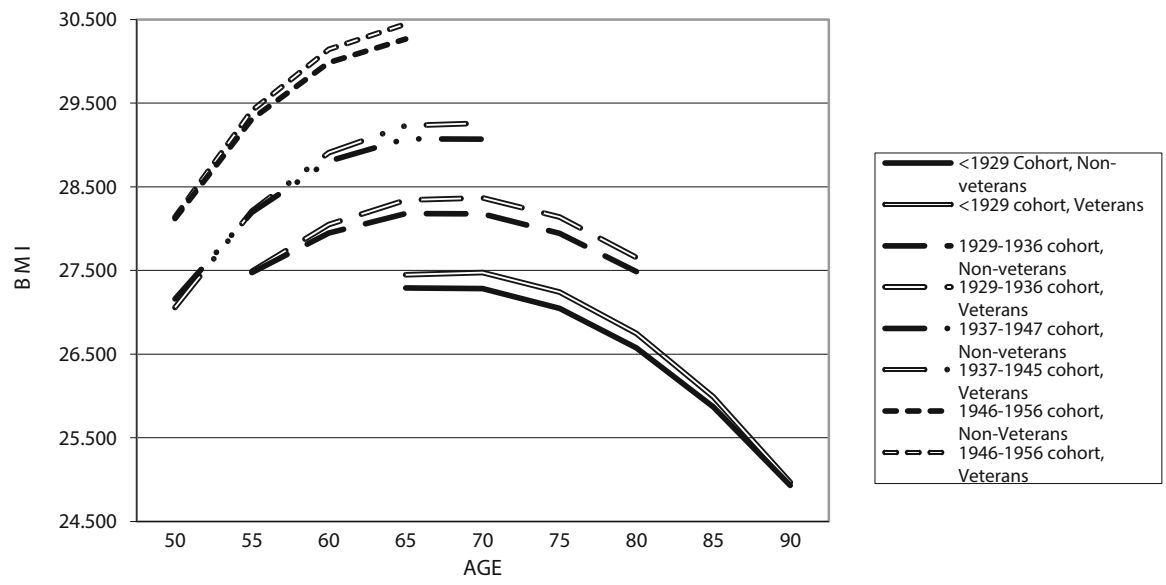

Fig. 7.1 Predicted BMI trajectories by birth cohort and veteran status

\section{Discussion}

This research examines whether age-related BMI trajectories among older men vary by veteran status. In order to compare veterans and non-veterans who came of age during different historical periods, we constructed a measure of birth cohort that corresponds to when respondents turned age 18 and became eligible to serve in the military, regardless of whether they actually entered the military. This approach allows us to examine intra-cohort veteran status differences and to account for those who served, respectively, during war and peacetime. While there are many reasons to expect that military service will contribute to lower body weight later in life, we find that veterans have slightly higher BMI than non-veterans and they have similar trajectories of weight change with age. Our key findings emerge across a set of hierarchical models. Without any controls in the models, veterans exhibit lower BMI, on average, than non-veterans. This would support the argument that military service provides protective effects against weight gain over the life course. However, since veterans are over-represented in older cohorts that have lower BMI, on average, the effect of veteran status reverses once cohort is controlled. Once we add controls for early-life characteristics that occur prior to military service, potentially mediating mid- to late-life characteristics, and methodological controls for proxy report, attrition, and death during the study period, the effect of veteran status is small, marginally significant, and positive-within each cohort, veterans are marginally heavier than their non-veteran counterparts. Although the effect of veteran status is small relative to the very large effect of cohort membership, the same can be said for other covariates that have been the focus of other individual-level studies of BMI, such as childhood disadvantage, Black and Hispanic race/ethnicity, and household income. Taken together, our analyses demonstrate the over-riding effect of the secular trend in increased weight across 
the population-younger cohorts are heavier than older cohorts regardless of their veteran status - and a substantively small but consistent, positive intra-cohort effect of veteran status.

We find the trajectory of weight change with age to be similar for veterans and non-veterans across cohorts. Overall, the predicted age pattern is slow weight gain across age until about age 65-70, followed by more-rapid weight loss at older ages. The two older cohorts, born before 1937, have significantly lower BMI, on average, than the two cohorts born after 1937. These two older cohorts also exhibit rapid declines in BMI in later life. Given that the younger two cohorts have not yet entered these later ages, it remains to be seen how their BMI trajectories will play out as they age into their eighties. The younger cohorts appear to have steeper increases in BMI with age during the early stages of later-life, although direct comparisons in trajectories across these earlier ages with the cohorts born before 1937 cannot be made because the older two cohorts were not observed during their early 50s. Other researchers using the HRS have found similar patterns over the age ranges of actual measurement (ages 51-75), but have not estimated predicted trajectories past that age range (Botoseneanu and Liang 2011; He and Baker 2004; Walsemann and Ailshire 2011).

Each successive cohort is most likely heavier because members of the younger cohorts experienced the well-documented late-twentieth century dietary changes in the United States earlier in their life course, and have lived with those eating patterns for a larger portion of their lives. Around 1970, diets in the United States began to shift toward increased consumption of soft drinks, snack food, and fast food in conjunction with lower consumption of fresh fruits and vegetables; portion size also increased along with total caloric intake, which has fueled the current obesity epidemic (Wang and Beydoun 2007). The youngest cohort in this analysis, which was born from 1946 to 1956, would have been 14-24 in 1970; the oldest cohort, which was born before 1929, would have been over 41 in 1970. Thus, our models demonstrate the cumulative effect of being exposed early in the life course to food consumption patterns that are associated with obesity. This trend towards heavier body size in younger cohorts, despite increases in physical activity, is mirrored in studies of active-duty military personnel (Lindquist and Bray 2000), as well as the general population.

Our research adds to the small body of work examining body size and veteran status. In line with some previous work (Almond et al. 2008; Wang et al. 2005), we find little substantive difference in body weight between veterans and non-veterans within the same cohort, although the estimated effect is marginally significant in the fully-specified model that includes a broad range of potentially mediating variables. In an analysis similar to ours, Teachman and Tedrow (2013) did find an effect of military service on body weight, with veterans being heavier. However, their analysis, based on men born after 1968, looks at a much younger and more recent cohort.

The physical demands and dietary control of military life contribute to an expectation that veterans should have lower body weight than non-veterans. Exercise and dietary habits formed in young adulthood might be expected to carry through to 
later life, resulting in lower overall weight and slower weight gain. However, our analyses show that the opposite is true. Veterans, if anything, are slightly heavier than their peers who did not experience military service. More-refined measures of current diet and levels of physical activity are needed to determine how these early-life habits change after leaving military service. One possible explanation is that eating habits acquired during active-duty service, when physical activities and caloric demands are high, do not change with exit from active-duty service and the shift to lower levels of physical activity (Teachman and Tedrow 2013). Another possibility is that the exercise and fitness regimes of the military contribute to veteran status differences in lean muscle to fat ratios, with such compositional differences contributing to veteran status differences in BMI and health across the life course (Koepsell et al. 2012).

Our analyses are limited by the constraints of the available data. While we are able to control for several early-life factors that are related to selection into the military and BMI, we do not have measures of early-life body weight. In addition, our measures of current BMI are based on self-reported measures of height and weight rather than on direct measurement. Self-reported BMI tends to be lower than directly measured BMI; however, veterans and non-veterans are similarly likely to under-report (Koepsell et al. 2012). Therefore, BMI is potentially influenced by normative bias, especially at the extreme ends of height and weight distributions. In addition, BMI itself is limited as a measure of obesity since it does not take into account differences in body composition. To the extent that veterans have greater muscle mass relative to body fat, BMI will overstate obesity. The findings might also mask important sources of BMI heterogeneity among veterans. For example, the effect of military service on BMI over the life course may operate through the lingering deleterious outcomes that are experienced by some military personnel who have engaged in combat, such as post-traumatic stress disorder and disabling physical injuries. Conversely, the military requirements for physical fitness might have had enduring positive effects for those who served as non-combat personnel, in particular branches of service, or in the officer ranks. Unfortunately, the HRS data upon which these analyses are based do not contain information about variation in veteran's military service experiences. When such data become available, future studies that examine heterogeneity in military service experiences have the potential to nuance our understanding of the influence of military service on mid- and late-life BMI trajectories.

Despite these limitations, this research contributes to our understanding of the complex ways that military service can impact later-life BMI and health. We are able to compare several cohorts of men who served in the military during different historical periods. We control for many early-, mid-, and late-life characteristics associated with selection into the military and health outcomes. Our finding of large cohort differences confirm other research documenting the secular trend towards increased body size in the general population (Flegal et al. 2010), while our finding of small, positive intra-cohort veteran status differences provides evidence that early-life institutional factors can have enduring effects across the life course. Despite the health habits related to exercise and fitness that are encouraged and 
enforced by the military, veterans were not protected from the broader social changes driving increases in BMI since the middle of the twentieth century. This finding has implications for policies that attempt to encourage healthy habits related to exercise and fitness in other institutional contexts in which young adults participate-namely higher education and prisons. While exercise promotion might have short-term impacts, it may not have enduring effects in a cultural context of unhealthy dietary practices.

It is not known whether the relationship between BMI and veteran status that we observe in this sample of older adult men in the United States would be found in other countries where the context of military service and trends in BMI differ. Similar to the United States, many older men in countries like England, France, Germany, Italy, Russia, China, and Japan served in the military during the middle of the twentieth century. These countries have also experienced rising BMI among more recent cohorts. Carefully conducted comparisons of cohort-specific BMI trajectories among veterans and non-veterans in other national contexts would enable researchers to determine the importance of military service relative to the influence of cohort membership and other individual-level characteristics, including health behaviors.

If datasets from other countries contain more detailed information about military service experiences, then such additional analyses could begin to identify the service-related factors that contribute to greater weight gain in later life. Until such studies are pursued, much can be learned by studying cross-cohort differences in military service experiences within a given country. For example, obtaining a better understanding how military policies regarding food rations during service and subsidized food in commissaries have varied across time could provide insight into how the food consumption patterns of military personnel and veterans might be different from the civilian non-veteran population in ways that would increase the risk of weight gain. Such research would also have implications for understanding the dietary practices and BMI of those who spend time in other institutional settings, like schools and prisons, which provide a large portion (if not all) of daily caloric intake to their members.

Both cross-national and single-country studies of the relationship between military service and BMI would benefit from employing a life course perspective that conceptualizes mid- to late-life outcomes as being rooted in experiences in childhood and young adulthood, and longitudinal models that capitalize on panel studies with steady state designs that follow successive cohorts as they age. Only then will the influence of military service on later-life health, and health-related outcomes like BMI, be fully understood. More importantly, such studies would advance life course research by providing insight into how specific pathways during the transition to adulthood and unique historical contexts experienced by particular cohorts shape later-life outcomes.

Acknowledgement This work was supported in part by NIH Grant \#1R01AG028480-01 (PI: Janet M. Wilmoth). 
Open Access This chapter is distributed under the terms of the Creative Commons Attribution Noncommercial License, which permits any noncommercial use, distribution, and reproduction in any medium, provided the original author(s) and source are credited.

\section{References}

Aldwin, C. M., Levenson, M. R., \& Spiro, A., III. (1994). Vulnerability and resilience to combat exposure: Can stress have lifelong effects? Psychology and Aging, 9(1), 34-44. doi:10.1037/0882-7974.9.1.34.

Almond, N., Kahawati, L., Kinsinger, L., \& Porterfield, D. (2008). Prevalence of overweight and obesity among U.S. military veterans. Military Medicine, 173, 544-549. doi:10.7205/MILMED.173.6.544.

Armed Forces Health Surveillance Center. (2009). Medical surveillance monthly report, 16(1), 1-28. http://www.dtic.mil/cgi-bin/GetTRDoc?AD=ADA495050\&Location=U2\&doc= GetTRDoc.pdf

Baltrus, P. T., Lynch, J. W., Everson-Rose, S., Ragthunathan, T. E., \& Kaplan, G. A. (2005). Race/ethnicity, life-course socioeconomic position, and body weight trajectories over 34 years: The Alameda County Study. American Journal of Public Health, 95, 1595-1601. doi:10.2105/AJPH.2004.046292.

Bedard, K., \& Deschênes, O. (2006). The long-term impact of military service on health: Evidence from World War II and Korean War veterans. American Economic Review, 96(1), 176-194. doi:10.1257/000282806776157731.

Beebe, G. W. (1975). Follow-up studies of World War II and Korean prisoners. II. Morbidity, disability, and maladjustments. American Journal of Epidemiology, 101(5), 400-422.

Bennett, P. R., \& McDonald, K. B. (2013). Military service as a pathway to early socioeconomic achievement for disadvantaged groups. In J. M. Wilmoth \& A. S. London (Eds.), Life-course perspectives on military service (pp. 119-143). New York: Routledge.

Botoseneanu, A., \& Liang, J. (2011). Social stratification of body weight trajectory in middle-age and older Americans: Results from a 14-year longitudinal study. Journal of Aging and Health, 23, 454-480. doi:10.1177/0898264310385930.

Burland, D., \& Lundquist, J. H. (2013). The best years of our lives: Military service and family relationships - a life-course perspective. In J. M. Wilmoth \& A. S. London (Eds.), Life-course perspectives on military service (pp. 165-184). New York: Routledge.

Centers for Disease Control. (1998). Health status of Vietnam veterans. II. Physical health. Journal of the American Medical Association, 259(18), 2708-2714. doi:10.1001/jama.1988.03720180034029.

Clarke, P., O'Malley, P. M., Johnston, L. D., \& Schulenberg, J. E. (2009). Social disparities in BMI trajectories across adulthood by gender, race/ethnicity and lifetime socio-economic position: 1986-2004. International Journal of Epidemiology, 38, 499-509. doi:10.1093/ije/dyn214.

Clipp, E. C., \& Elder, G. H., Jr. (1996). Aging veteran of World War II: Psychiatric and life course insights. In P. E. Ruskin \& J. A. Talbott (Eds.), Aging and posttraumatic stress disorder (pp. 19-51). Washington, DC: American Psychiatric Association Press.

Das, S. R., Kinsinger, L. S., Yancy, W. S., Wang, A., Ciesco, E., Burdick, M., et al. (2005). Obesity prevalence among veterans at Veterans Affairs medical facilities. American Journal of Preventive Medicine, 28(3), 291-294. doi:10.1016/j.amepre.2004.12.007.

Dobkin, C., \& Shabani, R. (2009). The health effects of military service: Evidence from the Vietnam draft. Economic Inquiry, 47(1), 69-80. doi:10.1111/j.1465-7295.2007.00103.x.

Elder, G. H., Jr. (1986). Military times and turning points in men's lives. Developmental Psychology, 22(2), 233-245. doi:10.1037/0012-1649.22.2.233.

Elder, G. H., Jr. (1987). War mobilization and the life course: A cohort of World War II veterans. Sociological Forum, 2(3), 449-472. doi:10.1007/BF01106621. 
Elder, G. H., Jr., \& Clipp, E. C. (1988). Combat experience, comradeship, and psychological health. In J. P. Wilson, Z. Harel, \& B. Kahana (Eds.), Human adaptation to extreme stress: From the Holocaust to Vietnam (pp. 131-156). New York: Plenum.

Elder, G. H., Jr., \& Clipp, E. C. (1989). Combat experience and emotional health: Impairment and resilience. Journal of Personality, 57(2), 311-341. doi:10.1111/j.1467-6494.1989.tb00485.x.

Elder, G. H., Jr., Shanahan, M. J., \& Clipp, E. C. (1997). Linking combat and physical health: The legacy of World War II in men's lives. American Journal of Psychiatry, 154(3), 330-336. doi:10.1176/ajp.154.3.330.

Elder, G. H., Jr., Clipp, E. C., Brown, J. S., Martin, L. R., \& Friedman, H. S. (2009). The lifelong mortality risks of World War II experiences. Research of Aging, 31(4), 391-412. doi:10.1177/0164027509333447.

Ferraro, K., Thorpe, R., \& Wilkinson, J. (2003). The life course of severe obesity: Does childhood overweight matter? The Journals of Gerontology. Series B, Psychological Sciences and Social Sciences, 58, S110-S119. doi:10.1093/geronb/58.2.S110.

Flegal, K. M., Carroll, M. D., Kuczmarski, R. J., \& Johnson, C. L. (1998). Overweight and obesity in the United States: Prevalence and trends, 1960-1994. International Journal of Obesity and Related Metabolic Disorders, 22, 39-47. doi:10.1038/sj.ijo.0800541.

Flegal, K. M., Carroll, M. D., Ogden, C. L., \& Curtin, L. R. (2010). Prevalence and trends in obesity among US adults, 1999-2008. JAMA, 303, 235-241. doi:10.1001/jama.2009.2014.

He, X. Z., \& Baker, D. W. (2004). Changes in weight among a nationally representative cohort of adults aged 51 to 61, 1992 to 2000. American Journal of Preventive Medicine, 27, 8-15. doi:10.1016/j.amepre.2004.03.016.

Health and Retirement Study (2008). Sample Evolution: 1992-1998. http://hrsonline.isr.umich. edu/sitedocs/surveydesign.pdf

Heflin, C. M., Wilmoth, J. M., \& London, A. S. (2012). Veteran status and material hardship: The moderating influence of disability. Social Service Review, 86(1), 119-142. doi:10.1086/665643.

Himes, C. L. (2000). Obesity, disease, and functional impairment in later life. Demography, 37, 73-82. doi:10.2307/2648097.

Hogan, D. P. (1981). Transitions and social change: The early lives of American men. New York: Academic.

Hsu, L. L., Nevin, R. L., Tobler, S. K., \& Rubertone, M. V. (2007). Trends in overweight and obesity among 18-year-old applicants to the U.S. military, 1993-2006. Journal of Adolescent Health, 41, 610-612. doi:10.1016/j.jadohealth.2007.07.012.

Institute of Medicine. (2008). Gulf war and health: volume 6. Physiologic, psychologic, and psychosocial effects of deployment-related stress. http://www.iom.edu/Reports/2007/GulfWar-Health-Vol-6-Physiologic-Psychologic-Psychosocial-Effects-Deployment-RelatedStress.aspx

Keehn, R. J. (1980). Follow-up studies of World War II and Korean conflict prisoners. III. Mortality to January 1, 1976. American Journal of Epidemiology, 111(2), 194-211.

Kleykamp, M. (2013). Labor market outcomes among veterans and military spouses. In J. M. Wilmoth \& A. S. London (Eds.), Life-course perspectives on military service (pp. 144-164). New York: Routledge.

Koepsell, T., Forsberg, C., \& Littman, A. (2009). Obesity, overweight, and weight control practices in U.S. veterans. Preventive Medicine, 23, 521-528. doi:10.1016/j.ypmed.2009.01.008.

Koepsell, T. D., Littman, A. J., \& Forsberg, C. W. (2012). Obesity, overweight, and their life course trajectories in veterans and non-veterans. Obesity, 20(2), 434-439. doi:10.1038/oby.2011.2.

Lindquist, C. H., \& Bray, R. M. (2000). Trends in overweight and physical activity among U.S. military personnel, 1995-1998. Preventive Medicine, 32, 57-65. doi:10.1006/pmed.2000.0771.

London, A. S., \& Wilmoth, J. M. (2006). Military service and (dis)continuity in the life course: Evidence on disadvantage and mortality from the Health and Retirement Study and the Study of Assets and Health Dynamics among the Oldest-Old. Research on Aging, 28(1), 135-159. doi:10.1177/0164027505281572. 
London, A. S., Heflin, C. M., \& Wilmoth, J. M. (2011). Work-related disability, veteran status, and poverty: Implications for family well-being. Journal of Poverty, 15(3), 330-349. doi:10.1080/10875549.2011.589259.

London, A. S., Burgard, S. A., \& Wilmoth, J. M. (2014). The influence of veteran status, psychiatric diagnosis, and traumatic brain injury on inadequate sleep. Journal of Sociology and Social Welfare, 41(4), 49-67.

Lutz, A. C. (2013). Race-ethnicity and immigration status in the U.S. military. In J. M. Wilmoth \& A. S. London (Eds.), Life-course perspectives on military service (pp. 68-96). New York: Routledge.

MacLean, A. (2010). The things they carry: Combat, disability, and unemployment among U.S. men. American Sociological Review, 75(4), 563-585. doi:10.1177/0003122410374085.

MacLean, A. (2013). A matter of life and death: Military service and health. In J. M. Wilmoth \& A. S. London (Eds.), Life-course perspectives on military service (pp. 200-220). New York: Routledge.

Miech, R. A., London, A. S., Wilmoth, J. M., \& Koester, S. (2013). The effects of the military's antidrug policies over the life course: The case of past-year hallucinogen use. Substance Use \& Misuse, 48, 837-853. doi:10.3109/10826084.2013.800120.

Mujahid, M. S., Diez Roux, A. V., Borrell, L. N., \& Nieto, F. J. (2005). Cross-sectional and longitudinal associations of BMI with socioeconomic characteristics. Obesity Research, 13(8), 1412-1421. doi:10.1038/oby.2005.171.

Narayan, K. M., Boyle, J. P., Thompson, T. J., Gregg, E. W., \& Williamson, D. F. (2007). Effect of BMI on lifetime risk for diabetes in the U.S. Diabetes Care, 30(6), 1562-1566. doi:10.2337/dc06-2544.

Nelson, K. M. (2006). The burden of obesity among a national probability sample of veterans. Journal of General Internal Medicine, 21(9), 915-919. doi:10.1007/BF02743137.

Ogden, C. L., Carroll, M. D., Kit, B. K., \& Flegal, K. M. (2012). Prevalence of obesity in the United States, 2009-2010 (NCHS data brief, Vol. 82). Hyattsville: National Center for Health Statistics.

Poston, W. S. C., Haddock, C. K., Peterson, A. L., Vander Weg, M. W., Klesges, R. C., Pinkston, M. M., \& DeBon, M. (2005). Comparison of weight status between two cohorts of U.S. Air Force recruits. Preventive Medicine, 40, 602-609. doi:10.1016/j.ypmed.2004.09.006.

Rosenberger, P. H., Ning, Y., Brandt, C., Allore, H., \& Haskell, S. (2011). BMI trajectory groups in veterans of the Iraq and Afghanistan wars. Preventive Medicine, 53(3), 149-154. doi:10.1016/j.ypmed.2011.07.001.

Sackett, P. R., \& Mayer, A. S. (Eds.). (2006). Assessing fitness for military enlistment: Physical, medical, and mental health standards. Washington, DC: The National Academies Press.

Sampson, R. J., \& Laub, J. H. (1996). Socioeconomic achievement in the life course of disadvantaged men: Military service as a turning point, circa 1940-1965. American Sociological Review, 61(3), 347-367. doi:10.2307/2096353.

Schnurr, P. P., Spiro, A., III, \& Paris, A. H. (2000). Physician-diagnosed medical disorders in relation to PTSD symptoms in older male military veterans. Health Psychology, 19(1), 91-97. doi:10.1037/0278-6133.19.1.91.

Teachman, J. (2011). Are veterans healthier? Military service and health at age 40 in the All-Volunteer Force era. Social Science Research, 40(1), 326-335. doi:10.1016/j.ssresearch.2010.04.009.

Teachman, J., \& Tedrow, L. (2013). Veteran status and body weight: A longitudinal fixed-effects approach. Population Research and Policy Review, 32(2), 199-220. doi:10.1007/s11113-012-9262-5.

U.S. Department of Health and Human Services. (2001). The surgeon general's call to action to prevent and decrease overweight and obesity. Rockville: US Department of Health and Human Services, Public Health Office, Office of the Surgeon General.

Vogt, D. S., King, D. W., King, L. A., Savarese, V. W., \& Suvak, M. K. (2004). Warzone exposure and long-term general life adjustment among Vietnam veterans: Findings from two perspectives. Journal of Applied Social Psychology, 34(9), 1797-1824. doi:10.1111/j.1559-1816.2004.tb02586.x. 
Walsemann, K. M., \& Ailshire, J. A. (2011). BMI trajectories during the transition to older adulthood: Persistent, widening, or diminishing disparities by ethnicity and education? Research on Aging, 33(3), 286-311. doi:10.1177/0164027511399104.

Wang, Y., \& Beydoun, M. A. (2007). The obesity epidemic in the United States-Gender, age, socioeconomic, racial/ethnic, and geographic characteristics: A systematic review and metaregression analysis. Epidemiologic Reviews, 29(1), 6-28. doi:10.1093/epirev/mxm007.

Wang, A., Kinsinger, L., Kahwati, L., Das, S., Gizlice, Z., Harvey, R., et al. (2005). Obesity and weight controls practices in 2000 among veterans using VA facilities. Obesity Research, 13, 1405-1411. doi:10.1038/oby.2005.170.

Whyman, M., Lemmon, M., \& Teachman, J. (2011). Non-combat military service in the United States and its effects on depressive symptoms among men. Social Science Research, 40(2), 695-703. doi:10.1016/j.ssresearch.2010.12.007.

Wilmoth, J. M., \& London, A. S. (Eds.). (2013). Life-course perspectives on military service. New York: Routledge.

Wilmoth, J. M., London, A. S., \& Heflin, C. M. (2015). Economic well-being among older-adult households: Variation by veteran and disability status. Journal of Gerontological Social Work, 58, 399-419.

Wilmoth, J. M., London, A. S., \& Parker, W. M. (2010). Military service and men's health trajectories in later life. The Journals of Gerontology. Series B, Psychological Sciences and Social Sciences, 56(6), 744-755. doi:10.1093/geronb/gbq072.

Wolf, D. A., Wing, C., \& Lopoo, L. M. (2013). Methodological problems in determining the consequences of military service. In J. M. Wilmoth \& A. S. London (Eds.), Life-course perspectives on military service (pp. 254-274). New York: Routledge. 